\title{
German adhesives industry is no. 1 worldwide
}

The German adhesives industry was able to increase its total sales for the sector by $3 \%$ in 2012 .

With $5.2 \%$ more sales, exports continue to make an important contribution to this increase.

$\mathrm{D}$ r. Boris Tasche, chairman of the German Adhesives Association (IVK), expects further export-driven growth for the current year. One reason for this optimism is the international character of the German adhesives industry. With its market share of approximately $16 \%$, it is the global market leader, and it is the no. 1 company in Europe with an adhesives consumption of $27 \%$ and a share of over $36 \%$ in adhesives production.

Worldwide sales of adhesives, sealants and adhesive tapes total $€ 55.5$ billion per year.

The German adhesives industry consists mainly of medium-sized companies and is positioned internationally. The majority of the companies produces in Germany and exports worldwide; however, about $20 \%$ of the companies serve the global markets from their local adhesives factories located outside of Germany.

Here's Dr. Boris Tasche: "With both business models, the German adhesives industry generates revenues of almost $€$ 9 billion." Exports for approx. € 1.4 billion are made from Germany, and further sales of $€ 7.5$ billion are generated locally by German adhesives manufacturers from their foreign production facilities. The German market has a sales volume of around $€ 3.5$ billion per year. The use of "adhesives systems devised in Germany" in almost all manufacturing branches of industry and in construction allows the adhesives industry to participate in the indirect creation of added value to the tune of over $€ 360$ billion in the domestic market. This corresponds with approximately $€ 1$ trillion worldwide.

This strong position is the immediate result of innovative technological developments, for example in mechanical engineering and plant construction, where the adhesives industry as system partner provides hands-on solutions which create added value.

In order to secure this innovation leadership in the future too, the Ger-

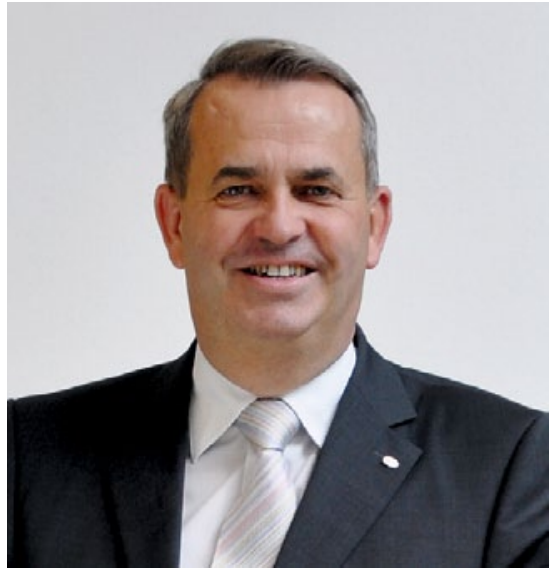

IVK chairman Dr. Boris Tasche: "Foreign business secures further growth for the German adhesives industry."

man Adhesives Association (IVK) is demanding the further development of research funding, i.e. that research should be supported in terms of taxes too. Of the approx. 13,253 employees organised in the German Adhesives Association, approx. 1,100 are employed in the divisions for development and application technology.

\section{WE CARE FOR YOUR SAFETY AND COMFORT SIKA AUTOMOTIVE}

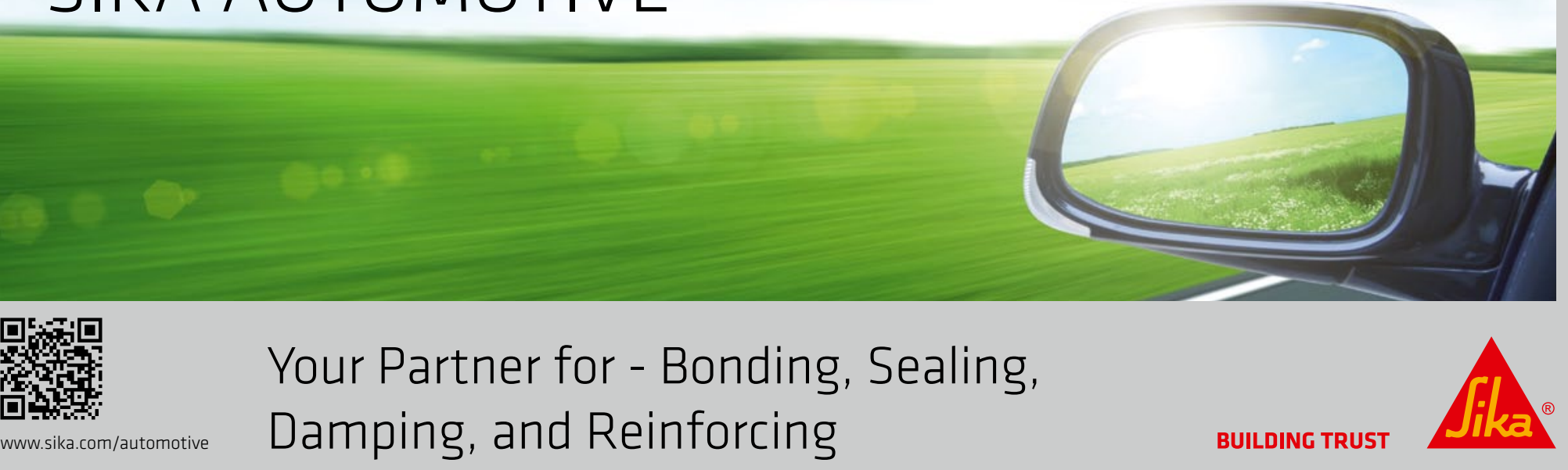

